\title{
The Effect of Microencapsulation of Phenolic Compounds from Lemon Waste by Persian and Basil Seed Gums on the Chemical and Microbiological Properties of Mayonnaise
}

\author{
Shima Shaygannia ${ }^{1}$, Mohammad Reza Eshaghi ${ }^{1}$, Mohammad Fazel ${ }^{2}$, and Mahnaz Hashemiravan ${ }^{1}$ \\ ${ }^{1}$ Department of Food Science and Technology, Islamic Azad University of Varamin-Pishva Branch, Varamin, Tehran 33317-74895, Iran \\ ${ }^{2}$ Department of Food Science and Technology, Islamic Azad University, Isfahan (Khorasgan) Branch, Isfahan 81595-158, Iran
}

\begin{abstract}
Natural preservatives with high level of phenolic compounds, antioxidants and antimicrobial activities are used in mayonnaise to improve quality and safety due to their potential health benefits. Application of these compounds in production processes highlights many difficulties due to instability of their physical and chemical properties. Microencapsulation is used to address these restrictions. In this study, phenolic compounds from lemon waste were encapsulated with Persian gum (PG) and basil seed gum (BSG) as coating materials at different ratios (0:1, 1:0, and 1:1) at 15\% (w/w) total biopolymer. We confirmed microencapsulation by scanning electron microscopy, and evaluate phenolic content, antioxidant activity, encapsulation efficiency, morphology, water solubility indexes, and water absorption indexes. Sample mayonnaise was prepared using microencapsulated polyphenols from lemon waste and extract (1,000 ppm of concentration), and control samples without extracts or microcapsules. All samples were subjected to chemical (measuring the peroxide, thiobarbituric acid, acidity, and color) and microbial (total count of microorganisms and Escherichia coli) analysis during 30 days of storage. BSG samples exhibited the highest antioxidant activity (61.19\%) and encapsulation efficiency (70.72\%), and PG/BSG microcapsules had the highest capability to prevent oxidative deterioration during storage. Addition of microcapsules led to increases in parameter $b^{*}$ and decreases in parameters $a^{*}$ and $L^{*}$. In general, PG/BSG microcapsules were considered optimal samples for production of mayonnaise, since they prevented mayonnaise deterioration and exhibited antioxidant and antimicrobial properties.
\end{abstract}

Keywords: basil seed gum, encapsulation, lemon waste, mayonnaise, Persian gum

\section{INTRODUCTION}

Mayonnaise is a widely consumed food product used as seasoning for different types of food (Liu et al., 2007). Due to its structure and composition, mayonnaise is highly susceptible to chemical and microbial deterioration. Chemical deterioration includes oxidation and hydrolysis of fat and oil types, which increases the content of compounds like peroxide, leading to sourness and changes to its color, taste, and texture (Frankel et al., 2002). Mayonnaise is susceptible to deterioration due to the structure of its lipid molecules, and their interactions with other molecules in their immediate vicinity, greatly influencing susceptibility to lipid oxidation (Coupland and McClements, 1996). Mayonnaise oxidation is intensified by free radicals generated from fat oxidation with other molecules like proteins, carbohydrates, and vitamins in the emulsion. In addition, undesirable changes in $\mathrm{pH}$ and acidity caused by microbial or chemical activity in mayonnaise leads to microbial deterioration (Shahidi and Zhong, 2005).

Therefore, synthetic antioxidants and chemical conservatives are added to mayonnaise to control oxidation and microbial activity, which has economic advantages despite the compounds being harmful to human health (Kwon et al., 2015). For example, the food conservative sodium benzoate inhibits activity of bacteria and fungi in acidic environments (e.g., in sauces and salad seasonings). However, sodium benzoate damages cell mitochondrial DNA, consequently inactivating the cell and leading to development of the Alzheimer's and Parkinson's diseases (Daescu et al., 1986).

Consumption of food prepared with natural sources of phenolic compounds with a wide range of antioxidant, 
antimicrobial, and anti-mutagenic activities has recently increased (Kong et al., 2003). In Iran, 650,000 tons of citrus are produced annually, which accounts for $9 \%$ of the global production (Vand and Abdullah, 2012).

Lemon is a species of citrus. The large amounts of lemon waste (peels, seeds, and pulps) produced by lemon juice industries have attracted attention. Lemon exhibits antimicrobial and antioxidant activity as it contains phenolic compounds, including flavonoids, coumarin, and limonene (Altunkaya et al., 2013).

Polyphenols contain a large group of bioactive compounds, and are present in fruit, vegetables, seeds, and other parts of plants. For humans, diet is one of the most important sources of polyphenols, which exhibit antioxidant properties and roles in food preservation and human health (Shariatifar et al., 2014). These compounds are sensitive to heat, light, and oxidation due to unsaturated bands within their molecular structures (Halliwell, 2008).

The strong antioxidant activity of phenolic compounds arises from their ability to scavenge free radicals. Indeed, radical scavenging activity is attributed to the presence of hydroxyl groups that replace aromatic rings. Phenolic compounds are present in many plant-based foods that have antioxidant activity (Lakshmanashetty et al., 2010).

Destruction of phenolic compounds can be prevented by microencapsulation, a process whereby bioactive compounds are trapped by biolipids, protecting them against the environment, thus increasing stability (BelščakCvitanović et al., 2011). Encapsulation can be achieved by biopolymers like starch compounds, agar, alginate, chitosan, and other gums (King, 1995). Arabic gum (AB) extracted from Acacia senegal trees is a type of polymer consisting of L-arabinose, D-galactose, and D-glucuronic acids and $2 \%$ pectin (Phillips and Williams, 2009) that is water soluble to produce a sticky solution. $A B$ is effective for microencapsulation because it generates a stable emulsion with different types of oil in different $\mathrm{pH}$ ranges, and is resistant to acidic conditions. Consequently, $\mathrm{AB}$ has a high stability and appropriate functionality in acidic compounds (Anandaraman and Reineccius, 1986).

Persian gum (PG) is composed of galactose and arabinose and is applied as an emulsifier in acidic $\mathrm{pH}$ emulsion systems, high salt foods, and thermal processes. Similar to other gums, PG is water soluble and produces a sticky and viscous solution (Golkar et al., 2018).

Basil seed gum (BSG) exhibits a heterosaccharide structure that includes glucomannan, glucan, and xylan. BSG is an exclusive hydrocolloid categorized as an anionic gum and is added as an active ingredient in food formulation to increase consistency and gelation and to control microstructure, texture and aroma during storage (Dickinson, 2003; Hosseini-Parvar et al., 2010).

In the present study, we extracted phenolic compounds from lemon waste (peels and edible pulps) and micro- encapsulated them in gel matrixes of PG and BSG as substitutes to synthetic antioxidants and sodium benzoate in mayonnaise production. We assessed the effects of encapsulation on physical, chemical, sensory, and microbial properties of mayonnaise over one month. These phenolic compounds may represent new preservatives and flavorings for use in mayonnaise formulation.

\section{MATERIALS AND METHODS}

\section{Materials}

The primary ingredients consumed during mayonnaise preparation (oil without antioxidants, vinegar, mustard, pasteurized eggs, sugar, and salt) were purchased from a local supermarket in Isfahan, Iran. Lemons were obtained from a local farm in Shiraz. AB was provided from SigmaAldrich Co. (St. Louis, MO, USA). BSG and PG were purchased from a local market in Isfahan, Iran. Folin-Ciocalteau's phenol reagent and 2,2-diphenyl-1-picrylhydrazyl hydrate (DPPH) were purchased from Merck KGaA (Darmstadt, Germany) and Sigma-Aldrich Co., respectively. Methanol, hexane, potassium chloride, trichloroacetic acid, and sodium bicarbonate were purchased from Sigma-Aldrich Co.. All other chemicals or solvents used were of analytical grade.

\section{Extraction of polyphenols from lemon waste}

Polyphenols were extracted from lemon by incubating $16 \mathrm{~g}$ lemon with $100 \mathrm{mg}$ of $70 \%$ ethanol in an ultrasonic bath $\left(60 \mathrm{~Hz}\right.$ frequency, $\left.60^{\circ} \mathrm{C}\right)$ for $2 \mathrm{~h}$. The extracts were removed by a vacuum rotary evaporator machine at $40^{\circ} \mathrm{C}$. The yield extract was filtered and then incubated in a freeze dryer for $48 \mathrm{~h}$ (Inoue et al., 2010).

\section{Preparation the PG and BSG}

Extraction of mucilage from Basil seeds was achieved following the method described by Hosseini-Parvar et al. (2010) with slight modifications. Extraction was performed using a water/seed ratio of $50: 1$ at $65^{\circ} \mathrm{C}, \mathrm{pH} 7$, for 20 min whilst stirring (500 rpm, RH basic 2, IKA, Staufen, Germany). A sterile extractor equipped with a rotating rough plate was used to separate the mucilage from the swollen seeds. The mucilage was then centrifuged and filtered to remove insoluble impurities. Finally, the filtrate was freeze-dried (Dena Vacuum, Tehran, Iran) at $-40^{\circ} \mathrm{C}$ for $24 \mathrm{~h}$ and stored under dry, cool, and sterile conditions.

PG was prepared according to methods described in previous studies (Fadavi et al., 2014; Golkar et al., 2015a; Golkar et al., 2015b). Briefly, impurities were removed from lighter colored PG samples and the samples were milled (AQC 109, Agromatic AG, Zürich, Switzerland) and sieved $(<500 \mu \mathrm{m})$. PG powder was then dissolved 
in distilled water with stirring $\left(23^{\circ} \mathrm{C}, 500 \mathrm{rpm}, \mathrm{RH}\right.$ basic 2 , IKA) for $2 \mathrm{~h}$ and stored in a refrigerator for $24 \mathrm{~h}$. The solution was centrifuged at 9,000 rpm for $15 \mathrm{~min}$ (PIT 320R, Hettichlab, Düsseldorf, Germany) to remove insoluble residues and the supernatant was collected and dried at $-40^{\circ} \mathrm{C}$ for $24 \mathrm{~h}$.

\section{Preparation of microcapsules}

PG and BSG were encapsulated using polyphenol compounds as coating agents following the method described by Rutz et al. (2013) with some modifications. To prepare the microcapsules, mixtures of hydrocolloids at different PG/BSG ratios (1:0, 1:1, and 0:1) with $15 \%(\mathrm{w} / \mathrm{w})$ total biopolymer were dissolved in water. Polyphenol extracts (containing $0.17 \mathrm{~g}$ of polyphenol) were then added so that the ratio of polyphenol extracts to wall material was 1:3. The mixture was stirred (500 rpm, RH basic 2 , IKA) for $12 \mathrm{~h}$ at room temperature $\left(23^{\circ} \mathrm{C}\right)$ and freeze dried (at $-40^{\circ} \mathrm{C}$ for $24 \mathrm{~h}$ ).

\section{Evaluation the of microcapsule properties}

Measurement of phenolic compounds: Phenolic compounds were measuring following the Folin-Ciocalteu method. First, $0.1 \mathrm{~g}$ of each sample was mixed with $20 \mathrm{~mL}$ methanol, and then rotated at $40^{\circ} \mathrm{C}$ to remove the methanol. Next, $0.5 \mathrm{~mL}$ diluted solution was added to $2.5 \mathrm{~mL}$ Folin reagent $(10 \mathrm{~g} / 100 \mathrm{~mL})$, and $2 \mathrm{cc}$ of $7.5 \%$ sodium carbonate solution was added. The obtained solution was then placed in the dark for $30 \mathrm{~min}$ before its absorption was measured at $760 \mathrm{~nm}$ (Ghasemi et al., 2009).

Measurement of the antioxidant activity: Antioxidant activity was determined following the method described by Brand-Williams et al. (1995), with modifications. First, $1 \mathrm{mg}$ of microcapsules were diluted in $1 \mathrm{~mL}$ methanolethanol solution $(50: 50, \mathrm{v} / \mathrm{v})$. The solution was incubated at $50^{\circ} \mathrm{C}$ for $20 \mathrm{~min}$, centrifuged at $9,000 \mathrm{rpm}$, and then $0.1 \mathrm{~mL}$ was added to $3.9 \mathrm{~mL}$ DPPH solution in laboratory tubes. After incubation in dark for $30 \mathrm{~min}$, the absorption was measured at $517 \mathrm{~nm}$. The inhibition percentage was calculated according to equation 1 :

Inhibition $(\%)=$

Sample absorption - Control absorption Sample absorption $\times 100$

Encapsulation efficiency: Encapsulation efficiency measured following the method described by Deladino et al. (2008) with slight modifications. To measure superficial phenolic compounds, $0.1 \mathrm{~g}$ of microcapsules were mixed with 5 $\mathrm{mL}$ methanol and centrifuged at 9,000 rpm for $10 \mathrm{~min}$. To measure total phenol compounds, $0.1 \mathrm{~g}$ of microcapsules were mixed with $1 \mathrm{~mL}$ ethanol: acetic acid: water solution (42:8:50), incubated in an ultrasonic bath for 20 min and centrifuged at 9,000 rpm. The total phenol vol- ume was measured following the Folin-Ciocalteu method and encapsulation efficiency were calculated according to equation 2:

Encapsulation efficiency $(\%)=$
Total phenolic compounds-
$\frac{\text { Superfitial phenolic compounds }}{\text { Total phenolic compounds }} \times 100$

Scanning electron microscopy (SEM): The microstructure of the microcapsules was examined by SEM (XL30, Philips, Guildford, UK). Samples were coated with gold/platinum at a thickness of about $15 \mathrm{~nm}$ and were analyzed by SEM (Zheng et al., 2011).

Water solubility index (WSI) and water absorption index (WAI): WSI and WAI were determined following the method described by Anderson (1982). Approximately $2.5 \mathrm{~g}$ of sample was suspended in $25 \mathrm{~mL}$ water, incubated in a water bath at $30^{\circ} \mathrm{C}$ for $30 \mathrm{~min}$, and centrifuged at 4,350 $g$ for $10 \mathrm{~min}$. The supernatant was collected in a preweighted petri dish and dried in a vacuum oven at $105^{\circ} \mathrm{C}$ for $24 \mathrm{~h}$. WSI was the amount of dry matter remaining following evaporation of the supernatant, expressed as a percentage of the dry matter in $2.5 \mathrm{~g}$ of sample. WAI was the weight of the solid pellet remaining after centrifugation divided by the amount of dry sample (Ahmed et al., 2011).

\section{Preparation of mayonnaise}

Mayonnaise was produced from the oil without antioxidant $(65.2 \%)$, pasteurized egg $(13.85 \%)$, water $(8.2 \%)$, vinegar $(7.7 \%)$, salt $(1.5 \%)$, and mustard $(0.3 \%)$ (all amounts are stated as \% w/w). First, eggs and the powdered materials (salt, sugar, mustard powder, and citric acid) were homogenized, and then oil was added until a mayonnaise emulsion had been formed. Next, vinegar was added to the mayonnaise emulsion, followed by additives (PG, BSG, or PG/BSG extracts; 1,000 ppm in all samples) and distilled water whilst mixing.

\section{Evaluation of the mayonnaise properties}

Acid value measurements: Lipids were extracted from mayonnaise samples according to the method described by AOAC (2005). The acidity of the extracted lipids was determined and expressed as acid value percentages.

Peroxide value (POV) measurements: POVs were determined according to the method described by Altunkaya et al. (2013), with slight modifications. First, the mayonnaise emulsion was broken and the oil was separated following the method described by Lagunes-Galvez et al. (2002). Here, the mayonnaise was frozen at $-40^{\circ} \mathrm{C}$ for $24 \mathrm{~h}$, allowed to thaw at $4^{\circ} \mathrm{C}$ for $24 \mathrm{~h}$, and then centrifuged at 4,000 rpm for $20 \mathrm{~min}$. Extracted oil (10 mg) was then dissolved in $2 \mathrm{~mL}$ methanol and butanol (1:1), $2 \mathrm{~mL}$ am- 
monium iron(II) sulfate, $45 \mathrm{mM}$ sulfuric acid, and 0.13 $\mathrm{M}$ ammonium thiocyanate. After $5 \mathrm{~min}$, the absorption was measured at $510 \mathrm{~nm}$ using a ultraviolet-visible spectrophotometer.

Thiobarbituric acid (TBA) measurements: TBA content was determined according to the method described by Tananuwong and Tewaruth (2010), with slight modifications. Briefly, $50 \mathrm{mg}$ of the oil phase of mayonnaise was mixed with butanol to $25 \mathrm{~mL}$, and $5 \mathrm{~mL}$ of this compound was mixed with TBA reagent and placed in water bath at $95^{\circ} \mathrm{C}$ for $2 \mathrm{~h}$. The absorption was measured at 530 $\mathrm{nm}$ using a spectrophotometer. TBA values was determined using equation 3 :

$$
\text { TBA value }=50 \times \frac{\left(\mathrm{A}_{\text {sample }}-\mathrm{A}_{\text {blank }}\right)}{\mathrm{m}}
$$

where $A_{\text {sample }}$ is absorbance of sample, $A_{\text {blank }}$ is absorbance of reagent blank, and $\mathrm{m}$ is the amount of oil sample amount (mg).

Color measurements: Color of the mayonnaise samples was measured using a ColorFlex $45^{\circ} / 0^{\circ}$ spectrophotometers (Hunter Associates Laboratory, Inc., Reston, VA, USA). The samples were assessed by comparing $L^{*}$ (transparency), $b^{*}$ (yellowness), and $a^{*}$ (redness) (Worrasinchai et al., 2006).

Microbiological assessment: Total bacterial counts (TBC) and Escherichia coli content was determined according to the methods described by APHA (1992) and Fan et al. (2008). Briefly, $25 \mathrm{~g}$ of mayonnaise samples were mixed with $225 \mathrm{~mL}$ of $0.85 \%$ sterile salt solution and the solutions were diluted. TBC was determined by plate count agar after incubation at $35^{\circ} \mathrm{C}$ for $48 \mathrm{~h}$ (Fan et al., 2008). $E$. coli content was determined by culture environs of $E$. coli with tryptone water, E. coli broth, and oxidative reagents (APHA, 1992).

\section{Statistical analysis}

Statistical analysis was performed based on completely randomized factorial design and analysis of variance (ANOVA) using SAS 9.1 software (SAS Institute Inc.,
Cary, NC, USA). Mean comparison tests were performed using least significant difference (LSD) methods at 5\% significant level.

\section{RESULTS AND DISCUSSION}

\section{Assessment of microcapsule properties}

Total phenolic content: The total phenolic contents of the extract and the different lemon waste microcapsules (PG and BSG) are shown in Table 1. The total phenolic content of lemon extract was $30.5 \pm 0.25 \mathrm{mg}$ gallic acid/g, which is consistent with that described in a previous study (Esparza-Martínez et al., 2016) in which the total phenolic content in extracts subjected to different temperature treatments ranged from 15.67 to $36.81 \mathrm{mg}$ gallic $\mathrm{acid} / \mathrm{g}$. The phenolic content of the lemon waste microcapsules depends on the compounds present in the core and wall materials. The highest and lowest total phenolic contents were observed for PG/BSG $(17.91 \pm 0.36 \mathrm{mg}$ gallic acid/g) and PG samples (13.92 $\pm 0.33 \mathrm{mg}$ gallic acid $/ \mathrm{g}$ ), respectively. PG is an ionic gum that creates mutual ion-dipole interactions with phenolic compounds, reducing phenolic content. Samples containing PG/BSG microcapsules may maintain higher amounts of phenolic compounds, while generating a particular structure with a high covering capability (Gharsallaoui et al., 2007). Single encapsulation of wall materials did not achieve all the required characteristics. However, the combination of different carbohydrates and proteins in multiple phenolic compounds may have acted to increase encapsulation efficiency.

Antioxidant activity: Hydroxyl radicals are the most reactive oxygen species, and can react effectively with biologic compounds including carbohydrates, DNA, polyunsaturated fatty acids, and proteins. Preventing these destructive reactions prolongs the permanence periods of the extracts (Youwei et al., 2008). The antioxidant activity of the phenolic extract and lemon waste microcapsules is shown in Table 1. Of the different microcapsules, BSG showed highest antioxidant activity (61.19 $\pm 0.34 \%)$,

Table 1. Total phenolic content, antioxidant activity, encapsulation efficiency, WSI and WAI of lemon waste extracts and microcapsules during storage

\begin{tabular}{lcccrc}
\hline Samples & $\begin{array}{c}\text { Total phenolic content } \\
\text { (mg gallic acid/g) }\end{array}$ & $\begin{array}{c}\text { Antioxidant } \\
\text { activity (\%) }\end{array}$ & $\begin{array}{c}\text { Encapsulation } \\
\text { efficiency (\%) }\end{array}$ & $\begin{array}{c}\text { WSI (g/100 g } \\
\text { dry solid) }\end{array}$ & $\begin{array}{c}\text { WAI (g/100 g } \\
\text { dry solid) }\end{array}$ \\
\hline BSG & $16.87 \pm 0.25^{\mathrm{b}}$ & $61.19 \pm 0.34^{\mathrm{b}}$ & $70.72 \pm 0.76^{\mathrm{a}}$ & $11.53 \pm 0.69^{\mathrm{a}}$ & $24.76 \pm 0.65^{\mathrm{c}}$ \\
PG/BSG & $17.91 \pm 0.36^{\mathrm{b}}$ & $58.23 \pm 0.81^{\mathrm{c}}$ & $67.07 \pm 0.46^{\mathrm{b}}$ & $8.33 \pm 0.27^{\mathrm{b}}$ & $32.51 \pm 0.60^{\mathrm{a}}$ \\
PG & $13.92 \pm 0.33^{\mathrm{c}}$ & $53.95 \pm 0.38^{\mathrm{d}}$ & $65.06 \pm 0.40^{\mathrm{b}}$ & $13.28 \pm 0.59^{\mathrm{a}}$ & $27.11 \pm 0.03^{\mathrm{b}}$ \\
Extract & $30.50 \pm 0.25^{\mathrm{a}}$ & $73.21 \pm 0.23^{\mathrm{a}}$ & - & - & - \\
\hline
\end{tabular}

The results were expressed as mean \pm standard deviation of three determinations.

Different letters $(a-d)$ in the column indicate significant differences $(P<0.05)$.

BSG, basil seed gum; PG, Persian gum; Extract, lemon extract free encapsulated; WSI, water solubility index; WAI, water absorption index. 
whereas PG showed had the lowest antioxidant activity $(53.95 \pm 0.38 \%)$. In general, samples containing BSG had high antioxidant activity, which may be attributed to the high content of phenolic compounds and presence of aromatic compounds in basil (Zheng et al., 2011). Similar observations were reported in a study by Ahmed et al. (2010) for $A B$ and maltodextrin as wall materials for purple sweet potatoes. The authors suggested that antioxidant activity depends on amounts of wall material and bioactive compounds, and that some biopolymers have antioxidant properties.

Many studies have shown a direct correlation between phenolic content and antioxidant properties, whereby PG /BSG samples with the highest phenolic compound contents have lower antioxidant properties compared with BSG samples. The antioxidant properties of polyphenols arise from their redox properties, which allow them to act as reducing agents, hydrogen donators, metal chelators, and single oxygen quenchers (Piluzza and Bullitta, 2011).

The antioxidant activity of lemon extracts was higher than that of the encapsulated samples. This may be attributed to deficient extraction of the phenolic compounds in microcapsules and extract reaction with the capsule membrane, leading to reduction in antioxidant activity. da Rosa et al. (2014) obtained similar results, indicating extract and microcapsule inhibition of $93.07 \%$ and 80.38 $\sim 90.75 \%$, respectively.

Encapsulation efficiency: Encapsulation efficiency indicates capability of the wall material in preserving core materials and is one of important factors for determining sustainability of capsulated compounds (Hogan et al., 2001). Encapsulation efficiency of the lemon waste extracts ranged from $65.06 \%$ to $70.72 \%$ (Table 1). Higher efficiencies were observed for BSG samples compared with the PG/BSG samples, attributed to its capability for film formation, biodegradability, and tendency to form a concentrated network in drying processes. This can be explained by the low functionality of PG and reduction of phenol compounds (Golkar et al., 2018). In addition, encapsulation efficiency depended on the type of encapsulated compounds, with the combination of extracts with different physical and chemical properties promoting different microcapsule behaviors. In a similar study, da Rosa et al. (2014) assessed the phenol compounds of blackberry with $\beta$-cyclodextrin gum, chitosan, and a mixture of both. The authors showed that encapsulation efficiency is influenced by the phenol compounds and the type of materials applied in the wall.

SEM: Fig. 1 shows the external structure and morphology of the microcapsules. The microcapsules coated with PG and PG/BSG showed irregular shapes, while the microcapsules coated with BSG showed smooth surfaces and uniform appearance, attributed to the chemical structures of the gum. Moreover, deep grooves were observed on the samples coated in BSG or PG/BSG, which might be due to the hydrophilic groups and enhancement of hydrogen bonds. The presence of deep and large grooves in the samples increased the sensitivity of the samples to oxidation. In general, the differences in the sample shapes could have arisen from differences in conductivity, concentration of the solution and the capsule contents.

In general, freeze-dried encapsulated powder had an irregular shape and flaky structure. Furthermore, micro grooves may be formed due to ice sublimation during freeze-drying. In a previous study, Pasrija et al. (2015) reported similar morphologies for freeze-dried microcapsules containing green tea polyphenols. SEM images of BSG showed that BSG has a fibril structure and contains a globular structure similar to that of the scattered cotton (Naji-Tabasi and Razavi, 2017).

WSI and WAI: In addition, release of the encapsulated compounds is influenced by solubility of the wall materials and absorption of solvent by the capsules. WSI and WSI of the microencapsulated lemon waste extracts are shown in Table 1. Samples containing PG demonstrated significantly higher $(P<0.05)$ water solubility $(13.28 \pm$ $0.59 \%)$, meaning that it can be easily and effectively dissolved and reconstituted in water for use with bioactive compounds in aqueous systems. Whereas PG/BSG sample showed the lowest water solubility, possibly due to cross-linking of the carbohydrates with other compounds, which reduces solubility and swelling power (Uslu and
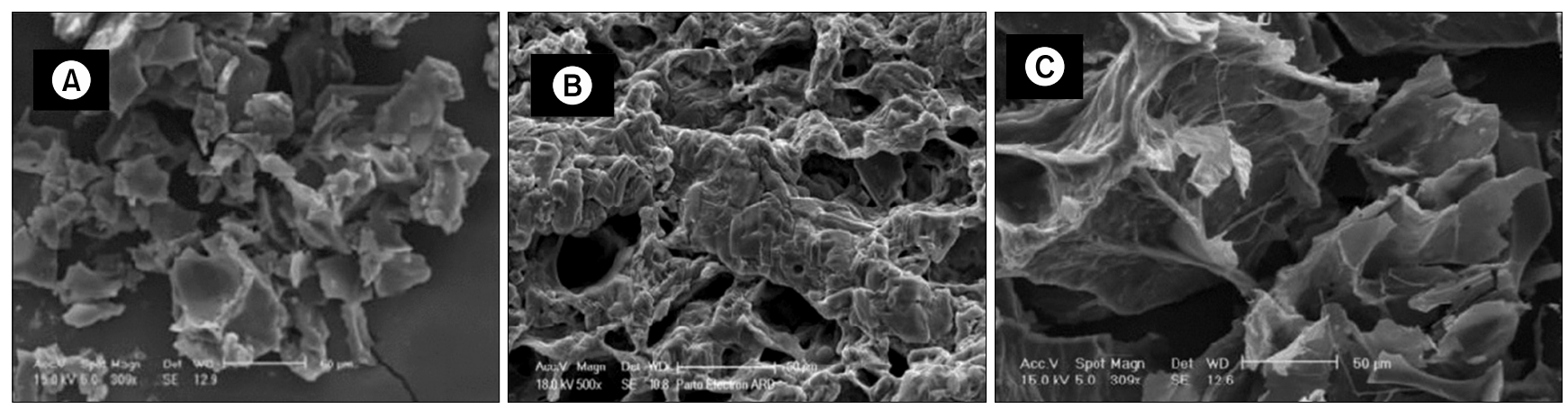

Fig. 1. SEM micrographs of encapsulated lemon waste extracts with PG (A), BSG (B), and PG/BSG (C). BSG, basil seed gum; PG, Persian gum. 
Polat, 2012). Tan et al. (2015) showed that WSI and WAI directly depend on the properties of the coating materials. In general, a high water solubility is important for application of powders in the food and pharmaceutical industries as it allows them to be easily incorporated into evenly distributed products.

Samples coated with PG/BSG showed the highest WAI $(32.51 \pm 0.60 \%)$, whereas lowest WAI were observed for those coated with PG $(24.76 \pm 0.65 \%)$. Therefore, samples coated with PG is less likely to be influenced by humidity and is more stable under storage conditions (Tan et al., 2015). These results suggest that the percentage of water absorption decreases with increased water solubility of the microcapsules. In a previous study, Moreira et al. (2009) obtained similar results for acerola pomace extracts. Furthermore, according to Ahmed et al. (2010) agglomeration of the encapsulated particles could contribute to a smaller WAI and, subsequently, increase WSI.

\section{Assessing the mayonnaise properties}

Acidity values: Acidity is one of important chemical features of salad sauces/dressings like mayonnaise. There is a direct relationship between storage duration and acidity. However, an increase in acidity leaves an unpleasant taste in the sauce. The acid values of the coated microencapsulated mayonnaise were gradually but significantly $(P<0.05)$ increased with the storage period, reaching the maximum level after 30 days (Table 2). The lowest acidity values during storage were observed for BSG samples, while the highest acidity values were observed for the control samples and the samples containing lemon waste extracts. This increase in acidity is attributed to the low $\mathrm{pH}$ of mayonnaise, which causes iron bridges between iron and phosvitin to break and release iron. Iron can activate oxidative and hydrolytic enzymes present in eggs (Stefanow, 1989; Kishk and Elsheshetawy, 2013). According to Kishk (1997), free fatty acids may be produced by oxidation of the double bonds of unsaturated fatty acid esters. Also, growth of acid-tolerant non-pathogenic bacteria, such as Lactobacillus, may be effective in this respect due to the water content of mayonnaise
(Karas et al., 2002). A high moisture content in mayonnaise during storage induces lipolysis followed by fat hydrolysis and accumulation of free fatty acids (Koczoñ et al., 2008). In a previous study, El-Bostany et al. (2011) assessed $\mathrm{pH}$ and acidity percentage of low-fat mayonnaise produced from potato powder. Over 60 days of storage, there was a reduction in $\mathrm{pH}$ and percentage increases in acidity.

POVs: POVs are qualitative parameters and indexes related to chemical deterioration of oils, and are considered a criterion for measuring hydroperoxide generated in products during the initial rate of oxidation (Alobo, 2001). Mayonnaise is an oil-in-water emulsion. The oil phase is susceptible to oxidative deterioration in connection with a vast surface of water, whereas the water phase contains high volumes of oxygen, which lead to increased oxidation (Gorji et al., 2016). In our study, POVs in the prepared mayonnaise samples were significantly $(P<0.05)$ increased throughout 30 days of storage.

After 30 days of storage, POV peaked at 27.32 \pm 0.1 $\mathrm{meqO}_{2} / \mathrm{kg}$ oil in the control samples, with significant differences $(P<0.05)$ observed compared with all other samples (Fig. 2). Samples containing PG/BSG exhibited lowest POVs $\left(10.40 \pm 0.11 \mathrm{meqO}_{2} / \mathrm{kg}\right.$ oil) within 30 days, followed by samples containing BSG $\left(12.40 \pm 0.31 \mathrm{meqO}_{2} /\right.$ $\mathrm{kg}$ oil). This can be related to the oxygen barrier characteristics of PG- and BSG-based encapsulation. Formation of hydroperoxides is further decreased in BSG samples due to antioxidant properties of BSG with phenolic and aromatic compounds, which reduce the POV (Milani and Golkar, 2019). In a previous study, Bagheri et al. (2015) revealed that fennel extracts prevent oil fat oxidation due to a high content of phenolic compounds. These results were determined by the antioxidant activity of the extracts and encapsulated extracts in preventing kilka fish oxidation, whereby the antioxidant effect was highest for the encapsulated extracts. Our results are consistent with the previous studies, indicating encapsulation has potential to improve antioxidant activity of the lemon extracts in mayonnaise by prolonging its availability.

Evidence of encapsulation improving bioactivity and bi-

Table 2. Acid values of mayonnaise samples prepared using extracts and microcapsules of lemon waste during storage

The results were expressed as mean \pm standard deviation of three determinations.

Different small letters $(a-e)$ in the same column and capital letters $(A-D)$ in the same row indicate significant $(P<0.05)$ differences during the 30-day storage.

Control, non-encapsulated samples; BSG, basil seed gum; PG, Persian gum; Extract, lemon extract free encapsulated. 


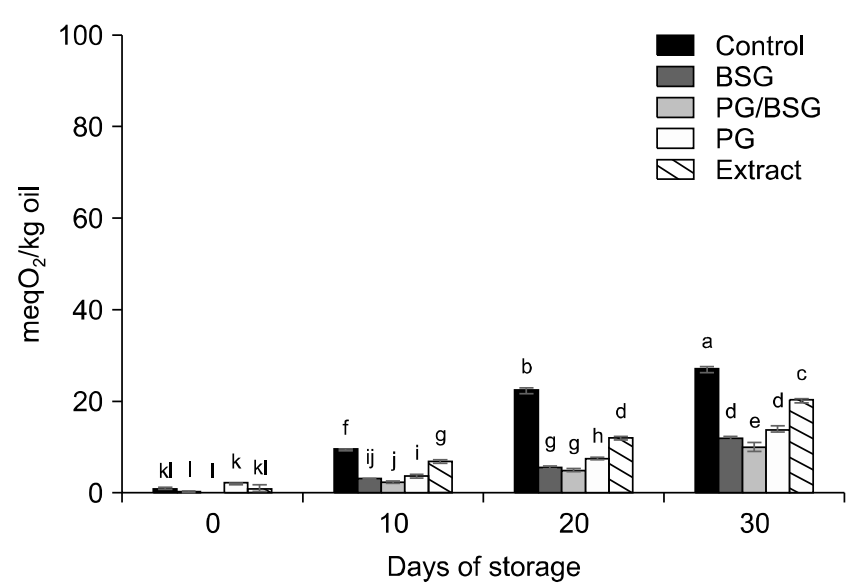

Fig. 2. Peroxide values $\left(\mathrm{meqO}_{2} / \mathrm{kg}\right)$ measured as peroxide and hydroperoxide concentrations in lipid extracts of mayonnaise samples prepared using extracts and microcapsules of lemon waste with PG and BSG during storage. Different letters (a-I) indicate significant $(P<0.05)$ differences between results. Values are mean \pm standard deviation of three experimental repeats. Control, non-encapsulated samples; BSG, basil seed gum; PG, Persian gum; Extract, lemon extract free encapsulated.

oavailability of polyphenols has been reported in previous studies (Fang and Bhandari, 2010). However, it has also been reported that higher concentrations of extracts may act as better pro-oxidants (Sarah et al., 2010). Rasmy et al. (2012) assessed the antioxidant effect of rosemary alcoholic extracts on mayonnaise formulation and found that applying $400 \mu \mathrm{g}$ of extract (concentration in $1 \mathrm{~g}$ of mayonnaise) reduced POV compared with the control group. Moreover, similar to the increase in POVs after 4 months, mayonnaise-containing rosemary followed a slower increase compared to butylated hydroxyanisole antioxidants.

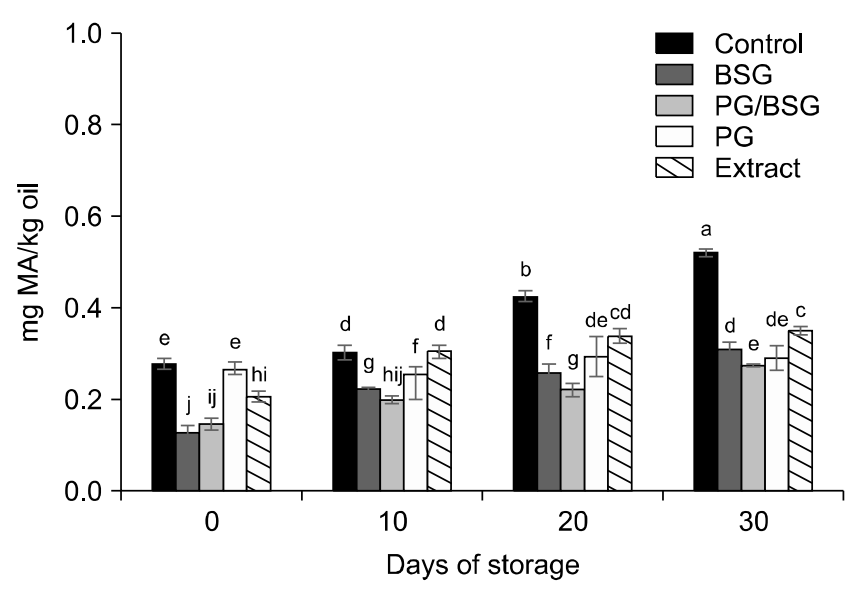

Fig. 3. Thiobarbituric acid (TBA) [mg malondialdehyde (MA)/kg] reactive substance value of lipid extracts of mayonnaise samples prepared using extracts and microcapsules of lemon waste with PG and BSG during storage. Different letters (a-j) indicate significant $(P<0.05)$ differences between results. Values are mean \pm standard deviation of three experimental repeats. Control, non-encapsulated samples; BSG, basil seed gum; PG, Persian gum; Extract, lemon extract free encapsulated.
TBA values: Primary oxidation products are highly instable, and therefore decompose rapidly into secondary oxidation compounds (Whitaker, 2001). TBA values were significantly $(P<0.05)$ increased in the prepared mayonnaise samples, with highest values observed after 30 days of storage. At the beginning of storage, TBA values are trivial because this index is formed due to hydroperoxide decomposition. Whereas during the storage period, hydroperoxide is converted into ketones and aldehydes (Daoud et al., 2019). Samples containing PG/BSG had the lowest TBA values [0.28 $\pm 0.04 \mathrm{mg}$ malondialdehyde (MA)/kg oil], and control samples had the highest TBA values $(0.52 \pm 0.01 \mathrm{mg} \mathrm{MA} / \mathrm{kg}$ oil, Fig. 3$)$ after 30 days of storage. The results emphasized that encapsulation of mayonnaise with PG and BSG coated lemon waste extracts decreases oxidation and increases the shelf-life. This can be attributed to the protective effects of encapsulation against oxygen and the antioxidant activity of phenolic compounds present in lemon waste extracts. In addition to encapsulation providing effective barriers against oxygen, BSG and PG significantly $(P<0.05)$ enhanced the antioxidative properties of encapsulation. The reduction in TBA values may therefore be attributed to phenolic compounds such as tannin, and antioxidative properties of Persian gums, and the antimicrobial effect of basil on fat oxidation-related bacterial-enzyme reactions (Buonocore et al., 2002). The lemon waste extracts had higher TBA value compared with the microcapsule samples, consistent with results from previous studies. For example, Gortzi et al. (2006) demonstrated that antioxidant activity was higher in thymus encapsulated with liposomes than that of non-encapsulated extracts.

Color evaluation: The results of color parameter $\left(\mathrm{L}^{*}, \mathrm{a}^{*}\right.$, and $\left.b^{*}\right)$ evaluation of the extracts and microencapsulated lemon waste polyphenols with different coating materials are shown in Table 3.

There were no significantly differences in the $L^{*}$ values of the control samples and extract samples. The lowest $L^{*}$ values were observed for BSG sample (85.30 \pm 0.10$)$.

Table 3. Color measurements of mayonnaise samples prepared using extracts and microcapsules of lemon waste during storage

\begin{tabular}{lccc}
\hline Samples & $L^{*}$ & $\mathrm{a}^{*}$ & $\mathrm{~b}^{*}$ \\
\hline Control & $91.77 \pm 0.24^{\mathrm{a}}$ & $-1.31 \pm 0.03^{\mathrm{a}}$ & $8.48 \pm 0.07^{\mathrm{b}}$ \\
BSG & $85.30 \pm 0.10^{\mathrm{d}}$ & $-1.73 \pm 0.02^{\mathrm{c}}$ & $8.51 \pm 0.13^{\mathrm{b}}$ \\
PG/BSG & $87.02 \pm 0.29^{\mathrm{c}}$ & $-1.68 \pm 0.06^{\mathrm{bc}}$ & $9.39 \pm 0.15^{\mathrm{ab}}$ \\
PG & $89.31 \pm 0.13^{\mathrm{b}}$ & $-1.58 \pm 0.03^{\mathrm{b}}$ & $10.21 \pm 0.06^{\mathrm{a}}$ \\
Extract & $91.63 \pm 0.20^{\mathrm{a}}$ & $-1.51 \pm 0.01^{\mathrm{b}}$ & $10.35 \pm 0.10^{\mathrm{a}}$ \\
\hline
\end{tabular}

The results were expressed as mean \pm standard deviation of three determinations.

Different letters $(a-d)$ in the column indicate significant differences $(P<0.05)$.

Control, non-encapsulated samples; BSG, basil seed gum; PG, Persian gum; Extract, lemon extract free encapsulated. 
Furthermore, the samples containing microcapsules had lower transparency compared with the control samples. The highest $\mathrm{a}^{*}$ values (red-green) were determined for the control samples $(-1.31 \pm 0.03)$, with the lowest values recorded for the BSG samples $(-1.73 \pm 0.2)$. In addition, the lowest $\mathrm{b}^{*}$ (green-blue) value was observed for the control sample.

Adding microcapsules to prepared mayonnaise samples decreased the $\mathrm{L}^{*}$ and $\mathrm{a}^{*}$ indexes, and increased the $\mathrm{b}^{*}$ indexes. The reduction in the $\mathrm{L}^{*}$ index is due to increases in particle diameter, which reduces light differentiation and product lightness. In a previous study, McClements and Demetriades (1998) reported that mayonnaise transparency decreases as the diameters of particles diameter in the emulsion increase.

Negative $a^{*}$ values were reported in the mayonnaise samples. This change in color toward greenness may be due to formation of phenolic polymer compounds. Adding PG increased yellowness $\left(b^{*}\right)$, whereas basil mucilage induced the opposite effect due to the color pigments in the extracts and gums. Our results are in line with those of a study by Amiri Aghdaei et al. (2014) which showed decreases in transparency $\left(\mathrm{L}^{*}\right)$ and yellowness $\left(\mathrm{b}^{*}\right)$ by addition of Plantago psyllium seed mucilage as an alternative to fat in low-fat mayonnaise.

Microbiological analysis: The total microbial count is presented in Fig. 4. Highest microorganism growth was observed in control samples, whereas samples containing BSG/PG and BSG had lowest microorganism growth during storage, indicative that encapsulation was effective in preventing microorganism growth. This antimicrobial

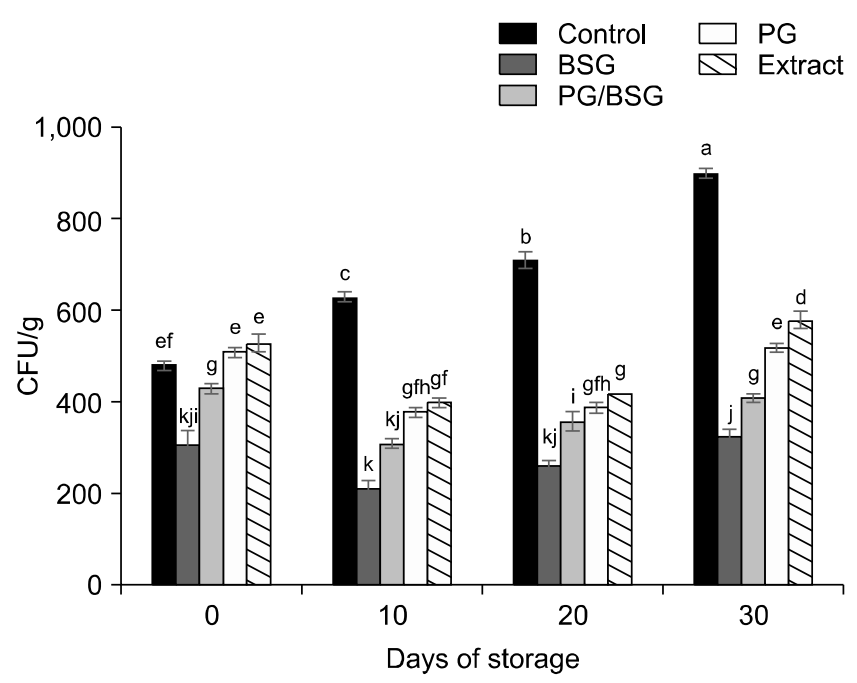

Fig. 4. Total bacterial counts of mayonnaise samples prepared using extracts and microcapsules of lemon waste with PG and BSG during storage. Different letters (a-k) indicate significant $(P<0.05)$ differences between results. Values are mean \pm standard deviation of three experimental repeats. Control, non-encapsulated samples; BSG, basil seed gum; PG, Persian gum; Extract, lemon extract free encapsulated; CFU, colony-forming unit. property is attributed to the phenolic compounds present in lemon extracts, PG and BSG, which inhibited microbial growth. Therefore, phenol compounds in lemon extracts, PG and BSG have antimicrobial activity against a wide spectrum of microorganisms (Buonocore et al., 2002). Indeed, BSG is a source of flavoring and antioxidants and contains essential oils, mainly 1,8-cineole, estragole and eugenol, flavonoids, and anthocyanin. BSG significantly increased antioxidant and antimicrobial properties of extracts compared with PG (da Costa et al., 2015).

In all samples, the total microorganism count was $<10^{3}$, resulting from organic acids in the mayonnaise reducing $\mathrm{pH}$ and acting as an antimicrobial material (Ma and Boye, 2013). All the samples indicated negative responses to Escherichia tests. When garden thyme extracts were added to mayonnaise, growth and activity of Salmonella enteritidis was inhibited in the presence of $0.4 \%$ extract. In a previous study, Juri et al. (2015) showed oregano essence inhibited growth of $S$. enteritidis in mayonnaise.

In the current study, microencapsulation of phenolic compounds extracted from the lemon waste was performed by PG, BSG, and BSG/PG. Highest EE and antioxidant activity were observed for sample coated with BSG $(70.72 \%$ and $61.19 \%$, respectively). Furthermore, we observed increased chemical stability of microencapsulated phenolic compounds. Samples containing microcapsules reduced peroxide production, stabilized free fatty acids, and prevented increases in acidity by eliminating and preventing formation of free radicals in the mayonnaise. Mayonnaise samples prepared using PG/BSG had significantly $(P<0.05)$ lowest peroxide and TBA values during the storage period compared with control samples. Moreover, microencapsulation decreased $\mathrm{L}^{*}$ and $\mathrm{a}^{*}$ indexes, and increased $\mathrm{b}^{*}$ indexes and were effective in reducing microbial growth and inhibiting Escherichia growth. Overall, polyphenol microcapsules from lemon waste have antioxidant and antimicrobial properties, and can be consumed as natural preservatives in mayonnaise.

\section{ACKNOWLEDGEMENTS}

The authors would like to acknowledge the Islamic Azad University (IAU), Khorasgan (Isfahan) Branch, for their valuable help, and cooperation with this project.

\section{AUTHOR DISCLOSURE STATEMENT}

The authors declare no conflict of interest. 


\section{REFERENCES}

Ahmed M, Akter MS, Lee JC, Eun JB. Encapsulation by spray drying of bioactive components, physicochemical and morphological properties from purple sweet potato. LWT-Food Sci Technol. 2010. 43:1307-1312.

Alobo AP. Effect of sesame seed flour on millet biscuit characteristics. Plant Foods Hum Nutr. 2001. 56:195-202.

Altunkaya A, Hedegaard RV, Harholt J, Brimer L, Gökmene V, Skibsted LH. Oxidative stability and chemical safety of mayonnaise enriched with grape seed extract. Food Funct. 2013. 4: 1647-1653.

Amiri Aghdaei SS, Aalami M, Babaei Geefan S, Ranjbar A. Application of Isfarzeh seed (Plantago ovate L.) mucilage as a fat mimetic in mayonnaise. J Food Sci Technol. 2014. 51:2748-2754.

Anandaraman S, Reineccius GA. Stability of encapsulated orange peel oil. Food Technol. 1986. 40:88-93.

Anderson RA. Water Absorption and solubility and amylograph characteristics of roll-cooked small grain products. Cereal Chem. 1982. 59:265-269.

AOAC. Official method of analysis of AOAC international. 18th ed. Association of Official Analytical Chemists, Washington, DC, USA. 2005. p 935-992.

APHA. Standard methods for the examination of water and wastewater. 18th ed. American Public Health Association, Washington, DC, USA. 1992. p 77-83.

Bagheri R, Izadi Amoli R, Tabari Shahndasht N, Shahosseini SR. Comparing the effect of encapsulated and unencapsulated fennel extracts on the shelf life of minced common kilka (Clupeonella cultriventris caspia) and Pseudomonas aeruginosa inoculated in the mince. Food Sci Nutr. 2015. 4:216-222.

Belščak-Cvitanović A, Stojanović R, Manojlović V, Komes D, Cindrić IJ, Nedović V, et al. Encapsulation of polyphenolic antioxidants from medicinal plant extracts in alginate-chitosan system enhanced with ascorbic acid by electrostatic extrusion. Food Res Int. 2011. 44:1094-1101.

Brand-Williams W, Cuvelier ME, Berset C. Use of a free radical method to evaluate antioxidant activity. LWT-Food Sci Technol. 1995. 28:25-30.

Buonocore GG, Del Nobile MA, Di Martino C, Gambacorta G, La Notte E, Nicolais L. Modeling the water transport properties of casein-based edible coating. J Food Eng. 2003. 60:99-106.

Coupland JN, McClements DJ. Lipid oxidation in food emulsions. Trends Food Sci Technol. 1996. 7:83-91. https://doi.org/10. 1016/0924-2244(96)81302-1.

da Costa AS, Arrigoni-Blank MF, de Carvalho Filho JLS, de Santana ADD, Santos DA, Alves PB, et al. Chemical diversity in basil (Ocimum sp.) germplasm. Sci World J. 2015. 2015: 352638. https://doi.org/10.1155/2015/352638

da Rosa CG, Borges CD, Zambiazi RC, Rutz JK, Luz SR, Krumreich FD, et al. Encapsulation of the phenolic compounds of the blackberry (Rubus fruticosus). LWT-Food Sci Technol. 2014. 58:527-533.

Daescu A, Constantin D, Crisan R, Iodchim A, Mate S, Iosif D. Manufacture of sodium benzoate. Rom Ro. 1986. 90:296-328.

Daoud S, Bou-maroun E, Dujourdy L, Waschatko G, Billecke N, Cayot P. Fast and direct analysis of oxidation levels of oil-inwater emulsions using ATR-FTIR. Food Chem. 2019. 293: 307-314.

Deladino L, Anbinder PS, Navarro AS, Martino MN. Encapsulation of natural antioxidants extracted from Ilex paraguariensis. Carbohydr Polym. 2008. 71:126-134.

Dickinson E. Hydrocolloids at interfaces and the influence on the properties of dispersed systems. Food Hydrocoll. 2003. 17:2539.

El-Bostany AN, Ahmed MG, Amany AS. Development of light mayonnaise formula using carbohydrate-based fat replacement.
Aust J Basic Appl Sci. 2011. 5:673-682.

Esparza-Martínez FJ, Miranda-López R, Guzman-Maldonado SH. Effect of air-drying temperature on extractable and non-extractable phenolics and antioxidant capacity of lime wastes. Ind Crops Prod. 2016. 84:1-6.

Fadavi G, Mohammadifar MA, Zargarran A, Mortazavian AM, Komeili R. Composition and physicochemical properties of Zedo gum exudates from Amygdalus scoparia. Carbohydr Polym. 2014. 101.1074-1080.

Fan W, Chi Y, Zhang S. The use of a tea polyphenol dip to extend the shelf life of silver carp (Hypophthalmicthys molitrix) during storage in ice. Food Chem. 2008. 108:148-153.

Fang Z, Bhandari B. Encapsulation of polyphenols - a review. Trends Food Sci Technol. 2010. 21:510-523.

Frankel EN, Satué-Gracia T, Meyer AS, German JB. Oxidative stability of fish and algae oils containing long-chain polyunsaturated fatty acids in bulk and in oil-in-water emulsions. J Agric Food Chem. 2002. 50:2094-2099.

Gharsallaoui A, Roudaut G, Chambin O, Voilley A, Saurel R. Applications of spray-drying in microencapsulation of food ingredients: an overview. Food Res Int. 2007. 40:1107-1121.

Ghasemi K, Ghasemi Y, Ebrahimzadeh MA. Antioxidant activity, phenol and flavonoid contents of 13 Citrus species peels and tissues. Pak J Pharm Sci. 2009. 22:277-281.

Golkar A, Nasirpour A, Keramat J, Desobry S. Emulsifying properties of Angum gum (Amygdalus scoparia Spach) conjugated to $\beta$-lactoglobulin through Maillard-type reaction. Int J Food Prop. 2015a. 18:2042-2055.

Golkar A, Nasirpour A, Keramat J. $\beta$-Lactoglobulin-Angum gum (Amygdalus scoparia Spach) complexes: preparation and emulsion stabilization. J Dispers Sci Technol. 2015b. 36:685-694.

Golkar A, Taghavi SM, Dehnavi FA. The emulsifying properties of Persian gum (Amygdalus scoparia Spach) as compared with gum Arabic. Int J Food Prop. 2018. 21:416-436.

Gorji SG, Smyth HE, Sharma M, Fitzgerald M. Lipid oxidation in mayonnaise and the role of natural antioxidants: a review. Trends Food Sci Technol. 2016. 56:88-102.

Gortzi O, Lalas S, Chinou I, Tsaknis J. Reevaluation of antimicrobial and antioxidant activity of Thymus spp. extracts before and after encapsulation in liposomes. J Food Prot. 2006. 69:29983005.

Halliwell B. Are polyphenols antioxidants or pro-oxidants? What do we learn from cell culture and in vivo studies?. Arch Biochem Biophys. 2008. 476:107-112.

Hogan SA, McNamee BF, O'Riordan ED, O'Sullivan M. Emulsification and microencapsulation properties of sodium caseinate /carbohydrate blends. Int Dairy J. 2001. 11:137-144.

Hosseini-Parvar SH, Matia-Merino L, Goh KKT, Razavi SMA, Mortazavi SA. Steady shear flow behavior of gum extracted from Ocimum basilicum L. seed: effect of concentration and temperature. J Food Eng. 2010. 101:236-243.

Inoue T, Tsubaki S, Ogawa K, Onishi K, Azuma J. Isolation of hesperidin from peels of thinned Citrus unshiu fruits by microwaveassisted extraction. Food Chem. 2010. 123:542-547.

Juri MH, Rouzbeh-Nasiraei L, Ghorbani SH. The antimicrobial effects of Mentha longifolia L. essential oil on Salmonella enteritidis in mayonnaise sauce. Iran J Food Microbiol. 2015. 2:15-26.

Karas R, Skvarča M, Žlender B. Sensory quality of standard and light mayonnaise. Food Technol Biotechnol. 2002. 40:119-127.

King $\mathrm{AH}$. Encapsulation of food ingredients: a review of available technology, focusing on hydrocolloids. In: Risch SJ, Reineccius GA, editors. Encapsulation and Controlled Release of Food Ingredients. American Chemical Society, Washington, DC, USA. 1995. p 26-39.

Kishk YFM, Elsheshetawy HE. Effect of ginger powder on the mayonnaise oxidative stability, rheological measurements, and sensory characteristics. Ann Agric Sci. 2013. 58:213-220. 
Kishk YFM. Role of some vegetable oils in mayonnaise characteristics. Master's thesis. Ain Shams University, Cairo, Egypt. 1997.

Koczoñ P, Gruczyñska E, Kowalski B. Changes in the acid value of butter during storage at different temperatures as assessed by standard methods or by FT-IR spectroscopy. Am J Food Technol. 2008. 3:154-163.

Kong JM, Chia LS, Goh NK, Chia TF, Brouillard R. Analysis and biological activities of anthocyanins. Phytochemistry. 2003. 64:923-933.

Kwon H, Ko JH, Shin HS. Evaluation of antioxidant activity and oxidative stability of spice-added mayonnaise. Food Sci Biotechnol. 2015. 24:1285-1292.

Lagunes-Galvez L, Cuvelier ME, Ordonnaud C, Berset C. Oxidative stability of some mayonnaise formulations during storage and daylight irradiation. J Food Lipids. 2002. 9:211-224.

Lakshmanashetty RH, Nagaraj VB, Hiremath MG, Kumar V. In vitro antioxidant activity of Vitex negundo L. leaf extracts. Chiang Mai J Sci. 2010. 37:489-497.

Liu H, Xu XM, Guo SD. Rheological, texture and sensory properties of low-fat mayonnaise with different fat mimetics. LWTFood Sci Technol. 2007. 40:946-954.

Ma Z, Boye JI. Advances in the design and production of reducedfat and reduced-cholesterol salad dressing and mayonnaise: a review. Food Bioprocess Technol. 2013. 6:648-670.

McClements DJ, Demetriades K. An integrated approach to the development of reduced-fat food emulsions. Crit Rev Food Sci Nutr. 1998. 38:511-536.

Milani JM, Golkar A. Introduction. In: Milani JM, editor. Some New Aspects of Colloidal Systems in Foods. IntechOpen, London, UK. 2019. https://doi.org/10.5772/intechopen.85298

Moreira GÉG, Costa MGM, de Souza ACR, de Brito ES, de Medeiros MFD, de Azeredo HMC. Physical properties of spray dried acerola pomace extract as affected by temperature and drying aids. LWT-Food Sci Technol. 2009. 42:641-645.

Naji-Tabasi S, Razavi SMA. Functional properties and applications of basil seed gum: an overview. Food Hydrocoll. 2017. 73:313-325.

Pasrija D, Ezhilarasi PN, Indrani D, Anandharamakrishnan C. Microencapsulation of green tea polyphenols and its effect on incorporated bread quality. LWT-Food Sci Technol. 2015. 64: 289-296.

Phillips GO, Williams PA. Gum arabic. In: Handbook of Hydrocolloids. Woodhead Publishing Ltd., Cambridge, UK. 2009. p 252-273.

Piluzza G, Bullitta S. Correlations between phenolic content and antioxidant properties in twenty-four plant species of trad- itional ethnoveterinary use in the Mediterranean area. Pharm Biol. 2011. 49:240-247.

Rasmy NM, Hassan AA, Foda MI, El-Moghazy MM. Assessment of the antioxidant activity of sage (Salvia officinalis L.) extracts on the shelf life of mayonnaise. World J Dairy Food Sci. 2012. 7:28-40.

Rutz JK, Zambiazi RC, Borges CD, Krumreich FD, da Luz SR, Hartwig N, et al. Microencapsulation of purple Brazilian cherry juice in xanthan, tara gums and xanthan-tara hydrogel matrixes. Carbohydr Polym. 2013. 98:1256-1265.

Sarah H, Hadiseh K, Gholamhossein A, Bahareh S. Effect of green tea (Camellia sinenses) extract and onion (Allium cepa) juice on lipid degradation and sensory acceptance of Persian sturgeon (Acipenser persicus) fillets. Int Food Res J. 2010. 17:751-761.

Shahidi F, Zhong Y. Lipid oxidation: measurement methodsedible oil and fat products: chemistry, properties, and safety aspects. In: Kamal-Eldin A, editor. Bailey's Industrial Oil and Fat Products. John Wiley \& Sons, Inc., Hoboken, NJ, USA. 2005. https://doi.org/10.1002/047167849X.bio050

Shariatifar N, Kamkar A, Shamse-Ardekani MR, Misagi A, Akhonzade A, Jamshidi AH. Composition and antioxidant activities of Iranian Pulicaria gnaphalodes essential oil in soybean oil. Pak J Pharm Sci. 2014. 27:807-812.

Stefanow L. Changes in mayonnaise quality. Lebensm Ind. 1989. 36:207-208.

Tan SP, Kha TC, Parks S, Stathopoulos C, Roach PD. Optimising the encapsulation of an aqueous bitter melon extract by spraydrying. Foods. 2015. 4:400-419.

Tananuwong K, Tewaruth W. Extraction and application of antioxidants from black glutinous rice. LWT-Food Sci Technol. 2010. 43:476-481.

Uslu MK, Polat S. Effects of glyoxal cross-linking on baked starch foam. Carbohydr Polym. 2012. 87:1994-1999.

Vand SH, Abdullah TL. Identification and introduction of thornless lime (Citrus aurantifolia) in Hormozgan, Iran. Indian J Sci Technol. 2012. 5:3670-3673.

Whitaker J. Current protocols in food analytical chemistry. John Wiley \& Sons, Inc., Hoboken, NJ, USA. 2001. p 4-5.

Worrasinchai S, Suphantharika M, Pinjai S, Jamnong P. $\beta$-Glucan prepared from spent brewer's yeast as a fat replacer in mayonnaise. Food Hydrocoll. 2006. 20:68-78.

Youwei Z, Jinlian Z, Yonghong P. A comparative study on the free radical scavenging activities of some fresh flowers in Southern China. LWT-Food Sci Technol. 2008. 41:1586-1591.

Zheng L, Ding Z, Zhang M, Sun J. Microencapsulation of bayberry polyphenols by ethyl cellulose: preparation and characterization. J Food Eng. 2011. 104:89-95. 